\title{
ARTE Y ESCUELA
}

Por Sonia Alexandra Barbosa Ortiz*1.

El presente ensayo, se centra en la búsqueda de sentido de la experiencia educativa, y para esto analiza relaciones entre tres conceptos articuladores como son arte, corporeidad y escuela.

Dado que todos los procesos de enseñanza-aprendizaje pretenden establecer relaciones con las experiencias cotidianas, se hace necesario puntualizar algunos componentes del concepto de experiencia. Luego de desarrollar el concepto de experiencia, se buscarán sus nexos con el arte, y luego se identificará cómo se entretejen con la corporeidad.

- Experiencia: la tradición occidental, desde la época moderna, se asienta en el desarrollo de un proyecto que compete a la humanidad entera: el progreso del conocimiento, el ensanchamiento de los límites del mundo conocido, de las facultades de conocer y de la comunidad de conocimiento. Toda investigación realizada se debe contemplar así como un tramo enlazado con una gran línea ininterrumpida que viene del conocimiento de quienes vivieron en el pasado, y se dirige a quienes vivirán en el futuro. La meta de la razón humana es construir un modelo del universo según el cual explicar las experiencias vividas y a la vez anticipar posibles experiencias del futuro, un sistema dentro del cual integrar, como partes, todo lo que pudiera ser conocido. Esto implica la construcción de pautas de pensamiento según las cuales formular preguntas a la captación sensible del mundo (percepciones, sensaciones, emociones), y así constituir experiencias.

Para John Dewey, el término 'experiencia' implica la unidad de las partes que constituyen la vida humana, dicha unidad sería el producto de una "cualidad determinada" que las impregna. Según Dewey "Tenemos una experiencia cuando el material experimentado sigue su curso hasta su cumplimiento, entonces y solo entonces se distingue ésta de otras experiencias y se integra dentro de la corriente general de la experiencia" (Dewey, 2008, págs. 41, 43), es decir, que se da

\footnotetext{
${ }^{1}$ Artista Plástica y pedagoga, Licenciada en Artes Plásticas de la Universidad Pedagógica y Tecnológica de Colombia, Magíster en Educación de la Universidad Externado de Colombia. Docente Pontificia Universidad Javeriana, en la Facultad de Artes Visuales. Correo: sonia.barbosa@unad.edu.co ORCID: http://orcid.org/0000-0003-4117-152X
} 
cumplimiento cuando la experiencia conforma un todo y lleva con ella su propia cualidad individualizadora y de autosuficiencia. Cada experiencia inicia como una

impulsión y deriva en un 'acto' que, según la máxima aristotélica, constituye el paso del no-ser al ser.

Aquello que llega a ser, se nos muestra como materia de posibles experiencias, pero sólo cuando logra expresarse se constituye en experiencia concreta. La expresión es manifestación de un pensamiento o sentimiento que se hace visible a través de diferentes modalidades, como gestos faciales o corporales, palabras, formas artísticas, etc. No obstante, cuando dice Dewey que "no hay expresión sin excitación, sin perturbación" (Dewey, 2008), se establece que la experiencia, al paso por la expresión, es una descarga o liberación de la compresión.

- El acto de expresión: si bien el acto es el paso del no-ser al ser, no hay garantía de que todo acto se constituya en experiencia. El acto de expresión, para Dewey, es una construcción, "una compresión o una presión" cultivada en el tiempo, y no sólo una emisión instantánea. Un acto de expresión se distingue de un simple acto del mismo modo que las uvas en el tonel se diferencian del zumo exprimido (Dewey, 2008).

La presente explicación se centrará ahora en cómo los conceptos de experiencia, acto, expresión y acto de expresión, se sitúan en contexto en la vida cotidiana, a través de lo que llamaremos 'comportamiento estético'. Si bien la experiencia construye la unidad de la vida humana, y su posibilidad es dada por la expresión, la vida, en tanto unidad de experiencia, no es meramente vivida sino vivida de modo consciente. Por otra parte, no basta que las cosas que acompañan la vida sean sin más, ya que todo lo que no exprese su ser puede pasar de largo sin hacerse materia de conciencia. Hace falta que esa "excitación y perturbación", que reclama Dewey a la expresión, hagan eco en nuestra rutina cotidiana. Hay varias maneras posibles de lograr la expresión, ya sea por la irrupción repentina de los acontecimientos, por la necesidad (el hambre, la escasez), o por el interés académico o investigativo profesional. De las posibles maneras de llegar a la expresión hay un tipo especial de sobresalto perturbador, que viene de la invitación del mundo mismo a saltar los cerrojos de la rutina, como sucede cuando estamos enamorados, cuando el mundo nos revela su belleza, cuando el ánimo mismo nos provee la emoción que expresa en nosotros el ser de lo que nos rodea, esto es lo que llamaremos 'comportamiento estético'.

Generado en el sujeto, el comportamiento estético exalta e intensifica su experiencia haciéndolo consciente de detalles y matices que ordinariamente pasan 
desapercibidos. De otros modos de llegar al comportamiento estético, la experiencia artística es destacable, en tanto lo logra de manera colectiva, superando las motivaciones biográficas particulares (gustos, fobias, caprichos) y trazando puentes sensibles entre los seres humanos. Como herramienta posibilitadora de la expresión, que no se desvincula de la vida ni del esfuerzo humano, el arte convoca a los seres humanos a compartir emociones, sensaciones e ideas. Gracias al impulso colectivo, en el arte se logran dos tipos de cumplimiento de la experiencia: la unificación de componentes de la vida y la unión de experiencias intersubjetivas entre colectivos humanos.

La principal razón que expone Dewey para destacar el arte como experiencia estética, es que el arte agencia de manera principal los modos de relación, entre lo cotidiano y lo extraordinario, ya que estos son los que establecen la expresión de la experiencia humana. Los productos que salen de estas relaciones son capaces de tocar sensibilidades y propician la transformación de quienes interactúan con una obra. Es decir que todo producto que promueva la interacción entre la vida y el contexto aplica como herramienta de sensibilización social. Según Dewey el arte es la prueba viviente y concreta de que el hombre es capaz de restaurar conscientemente, en el plano de la significación y en la unión de los sentidos, necesidades, impulsos y acciones características de la criatura viviente; el arte es una idea consiente, la más grande conquista intelectual de la historia de la humanidad.

A través de éstas reflexiones planteadas por Dewey se llega a la conclusión de que la experiencia, la expresión y el arte son inherentes al ser humano y producen aprendizajes que se mantienen en la memoria y son legados a las siguientes generaciones, es aquí donde el arte tiene que ver con la educación. Llegando a este punto se hace 'pertinente abordar las preguntas con que George Gadamer aporta una visión que hila en el cuerpo la relación entre experiencia y educación: ¿cuándo comienza la educación?, y ¿quién educa?

- Educación y corporeidad: el cuerpo es todo lo que somos, cuerpo que se alimenta, cuerpo que piensa, cuerpo que vive y muere. Toda la sociedad, en tanto participa de la producción y uso de los signos, las prácticas y los dispositivos tecnológicos, es una red de producción de afectos y subjetividades. El cuerpo, que es afirmado o negado por estas fuerzas presentes en la cultura y se va moldeando a través ellas, según la filósofa Consuelo Pabón, es "una masa múltiple y cambiante, capaz de construirse por transformaciones y devenires" (Pabón, 2000). Teniendo en cuenta que el cuerpo es la vida, y allí se manifiestan las fuerzas 
políticas, sociales, económicas, eróticas, etc., la pregunta que hace Consuelo es ¿Qué puede un cuerpo?

En tanto presencia social del yo, sobre el cuerpo recaen las fuerzas políticas y las prácticas de poder. Esto sugiere que en el cuerpo se tiene el control sobre la vida (biopoder); por lo tanto es un lugar privilegiado a través del cual se puede llegar a precipitar una transmutación de los valores de nuestra cultura, y en el cuál se ejerce, o no, la autonomía. Si bien el cuerpo es susceptible de ser herido, encerrado, torturado, anestesiado o controlado, su labor vital consiste en autoafirmar su potencia. En medio de la visión de experiencia que plantea Dewey por la vía de la expresión, el 'comportamiento estético' hace que el cuerpo aporte todo su sentido al mundo. Por esto la propuesta es liberar al cuerpo de la negatividad, haciendo un esfuerzo para salir de nosotros mismos, construir subjetivaciones o modos de existencia experimentales, donde se dé la posibilidad de imaginar y crear realidades diferentes cuando la dada nos agobia.

La visión de la educación que desarrolla Gadamer parte de la sospecha de que la aprobación de los otros es lo que la suscita, por ejemplo: si el niño intenta repetir una palabra que aún no interioriza y luego, a fuerza de repetirla, termina diciéndola adecuadamente (para los otros) es aplaudido, y entonces se siente satisfecho de haber hecho algo que es aceptado por los demás. Tal vez esa sea la manera como nosotros mismos nos vamos educando, (recibiendo la aprobación de los demás). "La educación es así un proceso natural, que a mi parecer, cada cual acepta siempre cordialmente procurando entenderse con los demás." (Gadamer, 1999) De este modo nos vamos aproximando poco a poco a lo que luego uno aprende en la escuela, es decir que un profesor no compite con todos estos elementos, dado que para un estudiante no es tan importante aprender un tema de una asignatura, como sí lo es encajar en una comunidad. El profesor, que interactúa durante gran parte del día con el estudiante, debería proporcionar una serie de experiencias significativas que contribuyan con el proceso de autopoiesis, ya que de lo que se trata es que el hombre acceda él mismo a su morada (Hegel, citado por Gadamer). Porque los seres humanos estamos rodeados de elementos que contribuyen con la producción de afectos (que afirman o niegan la vida) como los medios de comunicación, los amigos y enemigos, competidores, y en general las cosas que demanda la vida en su conjunto y que nos afectan por una u otra razón (y que no necesariamente están en la escuela), el profesor, dice Gadamer, "tiene una función muy modesta al querer influir en este proceso".

Por esta razón se hace necesario una escuela que comience por ofrecer experiencias en las que los sujetos modelen su propia construcción de cuerpo, 
experiencias fundadoras de corporeidades que queden en la memoria y que produzcan conocimiento (constituyendo experiencias de excitación y perturbación como reclama Dewey), y un profesor que sea detonador de cambios en las micro-políticas cotidianas.

\section{Bibliografía}

Dewey, J. (2008). El arte como experiencia. Barcelona: Paidos.

Gadamer, H. G. (1999). La educación es educarse. La educación es educarse (pág. 56). Buenos Aires: Paidós.

Pabón, C. (2000). Actos de fabulación Arte, cuerpo y pensamiento. En M. d. Cultura, Proyecto pentagono investigaciones sobre arte contemporaneo en Colombia (pág. 263). Bogotá: MInisterio de Cultura. 